\title{
ПОДХОДЫ К ФОРМИРОВАНИЮ МОДЕЛИ КЛЮЧЕВЫХ КОМПЕТЕНЦИЙ ЦИФРОВОЙ ЭКОНОМИКИ, СОГЛАСОВАННЫХ С КОМПЕТЕНЦИЯМИ ФГОС, С УЧЕТОМ ИХ ПРЕЕМСТВЕННОСТИ ПО УРОВНЯМ ВЫСШЕГО ОБРАЗОВАНИЯ
}

\author{
(c) 2021 Бакулина Анна Александровна
}

доктор экономических наук, профессор кафедры государственного управления

Московский государственный институт международных отношений МИД Российской Федерации, Россия, Москва

E-mail: anbakdoc@mail.ru

\section{(c) 2021 Чаленко Николай Николаевич}

преподаватель кафедры государственного управления

Московский государственный институт международных отношений МИД Российской Федерации, Россия, Москва

E-mail: n_chili@mail.ru

\section{(C) 2021 Солодовникова Кристина Игоревна}

главный специалист Отдела оценки ООО «Центр оценки собственности «МОРФ», Россия, Москва E-mail: kristina.solodovnikova@inbox.ru

Проведено исследование по формированию подходов к разработке модели ключевых компетенций цифровой экономики, согласованных с компетенциями, связанных с реализацией мероприятия федерального проекта «Кадры для цифровой экономики» национальной программы «Цифровая экономика Российской Федерации», направленных на достижение цели, определенной Указом Президента Российской Федерации от 21 июля 2020 года N 474 «О национальных целях развития Российской Федерации на период до 2030 года», которые будут способствовать достижению следующих целевых положений:

- совершенствование системы образования для обеспечения цифровой экономики компетентными кадрами;

- создание системы мотивации к освоению необходимых компетенций цифровой экономики;

- определение ключевых направлений трансформации рынка труда в соответствии с требованиями цифровой экономики.

Ключевые слова: компетентностный подход, цифровая экономика, цифрровые компетенции, компетенции ФГОС, уровни высшего образования.

Развитие цифровой среды меняет реальность во всех сферах экономики и общественного устройства. Вести деловые переговоры, заключать контракты, да и просто заказать услуги теперь можно онлайн. Форма такого взаимодействия, также все больше проникает в образовательную сферу, и, как это можно видеть на опыте большинства ВУЗов России во время «локдаунов», такая форма успешно применяется.

Существует два подхода к онлайн-обучению: синхронное и асинхронное. Синхронное обучение - взаимосвязь между студентами и преподавателями в «реальном времени» через Интернет [2]. Обычно это включает в себя такие инструменты, как:

- живой чат;

- аудио- и видеоконференции;

- обмен данными и приложениями;

- общая доска;

- виртуальное «поднятие руки»;

- совместный просмотр мультимедийных презентаций и онлайн-слайд-шоу.

Асинхронные методы обучения также используют возможности Интернета. Курсы по-прежнему проводятся при содействии инструкторов, но не в режиме реального времени, что означает, что учащиеся и преподаватель могут участвовать в мероприятиях, связанных 
с курсом, в удобное для них время, а не во время специально скоординированных занятий в классе.

Обычно это включает в себя такие инструменты, как:

- электронная почта;

- многопоточное обсуждение;

- группы новостей и доски объявлений;

- вложения файлов.

В асинхронных курсах обучение не должно планироваться так же, как в синхронных, что позволяет студентам и преподавателям пользоваться преимуществами обучения в любое время и в любом месте.

Вместе с тем, разработка образовательных курсов, как для синхронного, так и для асинхронного обучения должны согласовываться с установленной в российской системе образования концепцией, которая подразумевает развитие компетенций при обучении.

В этом случае возникает необходимость согласования цифровых компетенций и компетенций, установленных федеральными стандартами, для чего нужно формирование переходной модели и модели согласованности.

При формировании такой модели для наиболее широкого ее применения можно основывать на 5-ти ключевых компетенциях цифровой экономики согласно Приказу Минэкономразвития от 24 января 2020 г. N 41 «Об утверждении методик расчета показателей федерального проекта «Кадры для цифровой экономики» [4] Национальной программы «Цифровая экономика Российской Федерации».

Исходя из компетенций, представленных в вышеуказанном приказе, нами предлагаются компетенции общепрофессиональной направленности в цифровой экономике, в соответствии с уровнями высшего образования (таблица 1).

Важно отметить, что каждая компетенция должна обладать набором индикаторов сформированности и уровнями сформированности. Нам представляется возможным подразделять компетенции на начальный, средний и продвинутый уровни. Матрица согласования ключевых компетенций цифровой экономики с компетенциями федеральных государственных образовательных стандартов высшего образования может иметь вид таблицы 2.

Вместе с тем, цель построения модели формирования ключевых компетенций цифровой экономики, обеспечивающей согласованность ключевых компетенций цифровой экономики с компетенциями ФГОС, а также их преемственность по уровням высшего образования, видится нам как инструмент формирования базы для последующего формирования профессиональных компетенций (в сфере цифровой экономики) после освоения/параллельно с освоением общепрофессиональных компетенций (ОПК). В силу того, что профессиональные компетенции присущи формату профессионального стандарта, несущие контекст конкретной профессиональной деятельности, для примера, обосновывающего предлагаемый подход, мы сформировали матрицу соотношения общих трудовых функций, описанных в профессиональных стандартах, и освоенных выпускниками вуза общепрофессиональных компетенций. В качестве примера составления матрицы были рассмотрены трудовые функции Профессионального стандарта «Специалист по научноисследовательским и опытно-конструкторским разработкам», с ОПК-1 по направлению 01.03.01 Математика - уровень подготовки - бакалавриaT.

Матрица соотношения трудовых функций, составляющих профессиональную деятельность с ОПК, может позволить расширить возможности использования модели формирования ключевых компетенций цифровой экономики, обеспечивающей согласованность ключевых компетенций цифровой экономики с компетенциями ФГОС.

Данное исследование не является исчерпывающим, и будет нами развито в дальнейших научных работах.

\section{Выводы}

Предлагаемая модель формирования ключевых компетенций цифровой экономики (таблица 2) способна обеспечивать согласованность ключевых компетенций цифровой экономики с компетенциями ФГОС, а также их преемственность по уровням высшего образования. Вместе с тем подход, предложенный нами, обеспечивает переход к формированию цифровых компетенций профессиональной направленности, тем самым создает возможные условия для внедрения ключевых компетенций цифровой экономики в профессиональные стандарты. 


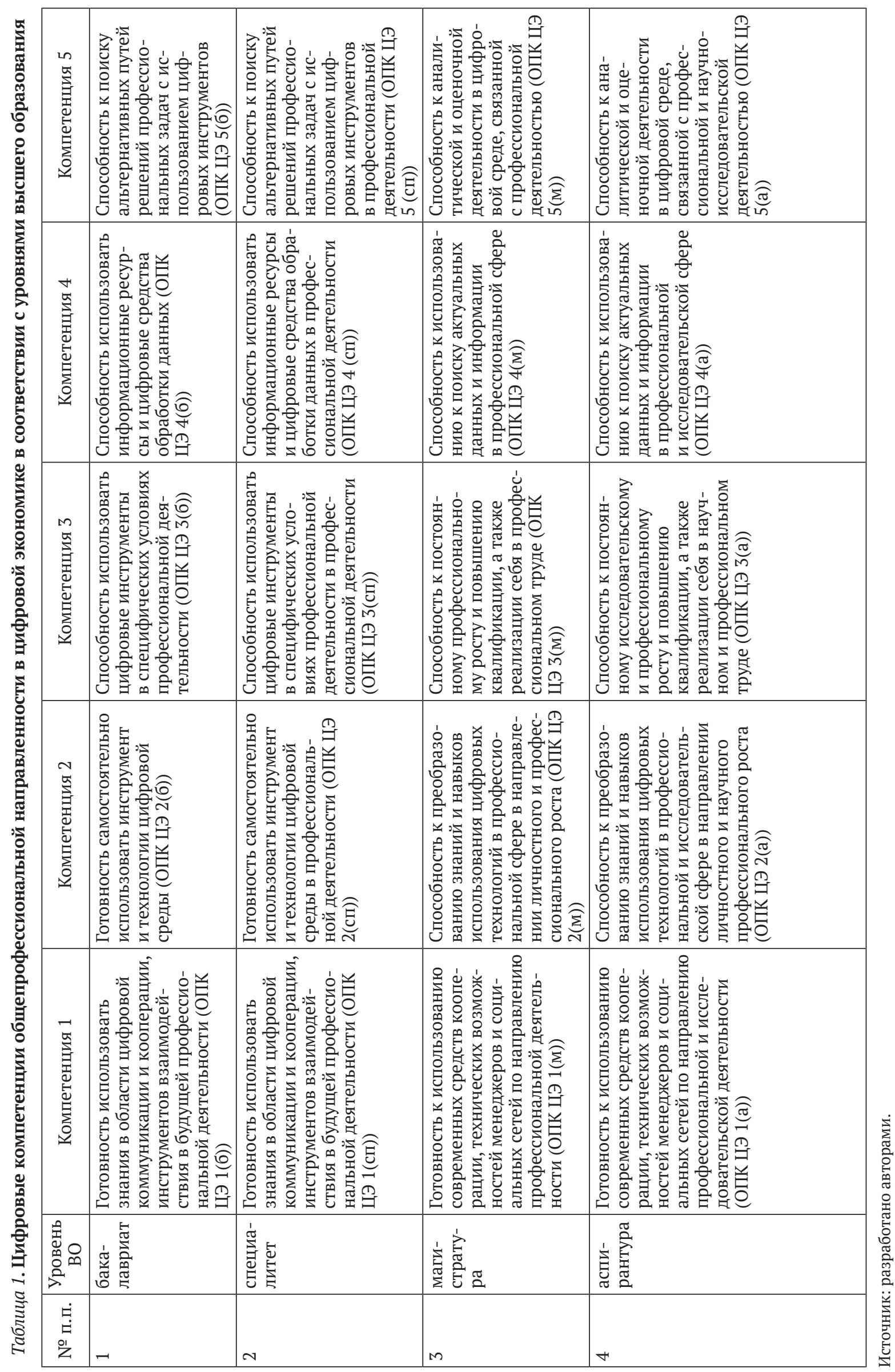




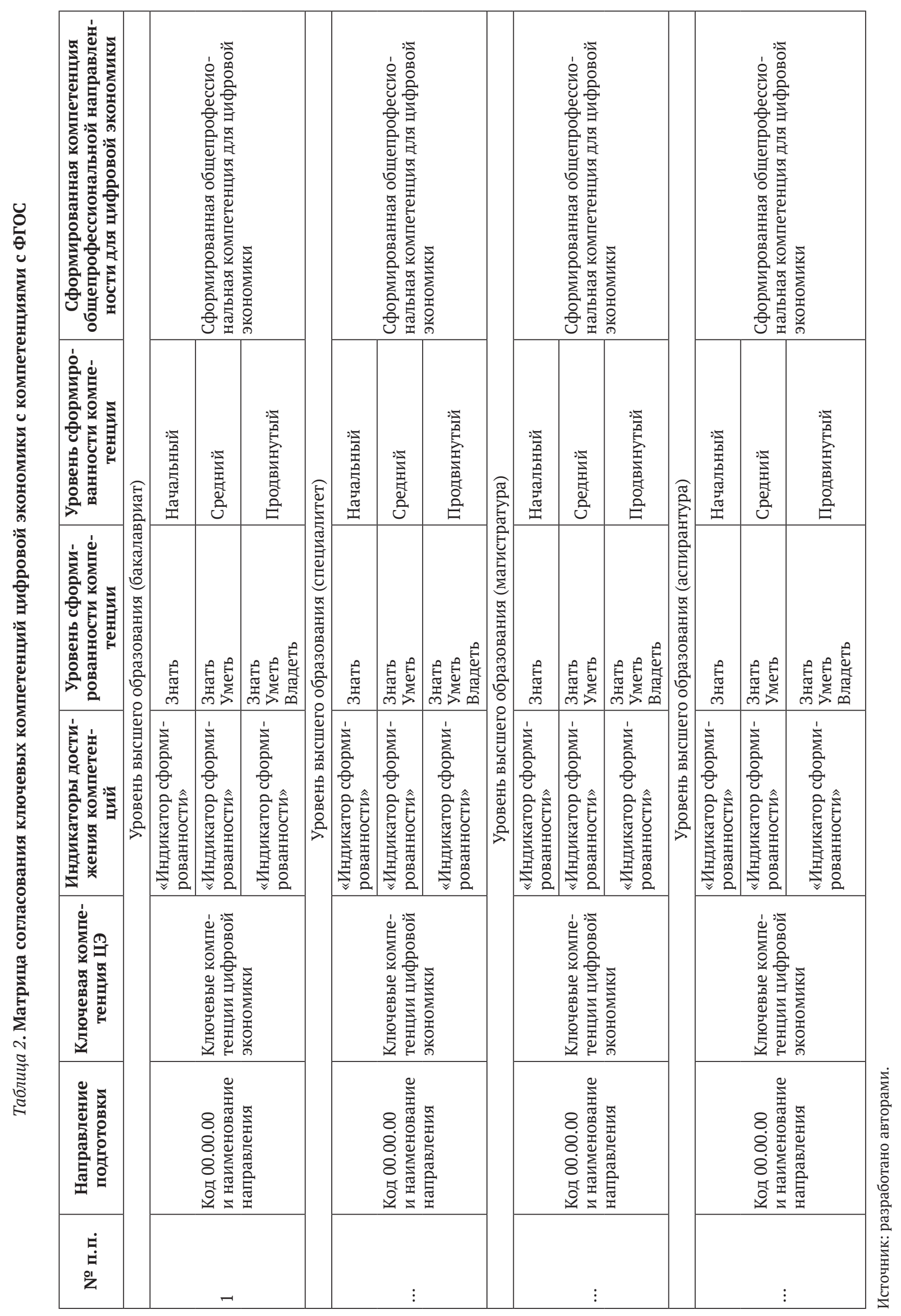


Таблица 3. Матрица соотношения трудовых функций, составляющих профессиональную деятельность с ОПК

\begin{tabular}{|c|c|c|c|c|}
\hline \multicolumn{3}{|c|}{$\begin{array}{l}\text { Трудовая функция - Проведение научно-исследовательских } \\
\text { и опытно-конструкторских разработок по отдельным разделам } \\
\text { темы }\end{array}$} & \multicolumn{2}{|c|}{$\begin{array}{l}\text { ОПК-1 - Способен применять фундамен- } \\
\text { тальные знания, полученные в области } \\
\text { математических и (или) естественных } \\
\text { наук, и использовать их в профессиональ- } \\
\text { ной деятельности }\end{array}$} \\
\hline Знать & Уметь & $\begin{array}{r}\text { Трудовь } \\
\text { ств }\end{array}$ & Знания & Умения \\
\hline $\begin{array}{c}\text { знать основные } \\
\text { понятия, принципи- } \\
\text { альные результаты } \\
\text { и методы матема- } \\
\text { тической логики, } \\
\text { алгебры и теории } \\
\text { чисел }\end{array}$ & $\begin{array}{c}\text { уметь решать } \\
\text { стандартные задачи } \\
\text { математической } \\
\text { логики, алгебры } \\
\text { и теории чисел. }\end{array}$ & $\begin{array}{c}\text { Проведение наблю- } \\
\text { дений и измерений, } \\
\text { составление их } \\
\text { описаний и } \\
\text { формулировка вы- } \\
\text { водов }\end{array}$ & $\begin{array}{c}\text { Основ математи- } \\
\text { ческого анализа, } \\
\text { комплексного } \\
\text { и функционального } \\
\text { анализа, алгебры }\end{array}$ & $\begin{array}{c}\text { Применять фунда- } \\
\text { ментальные знания } \\
\text { в области матема- } \\
\text { тического анали- } \\
\text { за, комплексного } \\
\text { и функционального } \\
\text { анализа, алгебры, }\end{array}$ \\
\hline
\end{tabular}

Источник: разработано авторами на основе [5].

\section{Библиографический список}

1. Беляева E.О., Катаев С.Г., Да Силва Перон Тиаго, Константинова Е. Количественное оценивание уровня сформированности компетенций и модель специалиста // Ped.Rev.. 2018. № 4 (22). URL: https://cyberleninka. ru/article/n/kolichestvennoe-otsenivanie-urovnya-sformirovannosti-kompetentsiy-i-model-spetsialista (дата обращения: 29.11.2021).

2. Козлова Д.А.Дистанционное обучение как инновационный подход в реализации непрерывного образования // Вестник Таганрогского института имени А.П. Чехова. 2013. № 1c. URL: https://cyberleninka.ru/ article/n/distantsionnoe-obuchenie-kak-innovatsionnyy-podhod-v-realizatsii-nepreryvnogo-obrazovaniya (дата обращения: 29.11.2021).

3. Пискунова К.Е., ЕрохинаЛ.Ю.Общепрофессиональные компетенции сквозь призму профессионального стандарта // Мир науки. Педагогика и психология. 2017. № 4. URL: https://cyberleninka.ru/article/n/ obscheprofessionalnye-kompetentsii-skvoz-prizmu-professionalnogo-standarta (дата обращения: 29.11.2021).

4. Приказ Минэкономразвития России от 24 января 2020 г. № 41 «Об утверждении методик расчета показателей федерального проекта «Кадры для цифровой экономики национальной программы «Цифровая экономика Российской Федерации». URL: https://economy.gov.ru/material/dokumenty/prikaz_minekonomrazvitiya_ rossii_ot_24_yanvarya_2020_g_41.html

5. Специалист по научно-исследовательским и опытно-конструкторским разработкам. URL: https:// profstandart.rosmintrud.ru/obshchiy-informatsionnyy-blok/natsionalnyy-reestr-professionalnykh-standartov/ reestr-professionalnykh-standartov/index.php? ELEMENT_ID=57015 